\title{
Polyphenolic Biosensors. Application in Red Wines
}

\author{
C. I. S. Fernandes, ${ }^{*}$ M. J. F. Rebelo \\ CCMM -Faculdade de Ciências da Universidade de Lisboa, Campo Grande, C 8, \\ 1749-016 Lisboa, Portugal
}

Received 6 January 2009; accepted 5 May 2009

\begin{abstract}
New developments in the utilization of a laccase based polyphenolic biosensor were done in order to optimize its application in wines. Laccase was immobilized on polyether sulphone membranes and applied on an Universal Sensors (US) electrode base system containing a platinum working electrode and silver, silver chloride electrode.

Caffeic acid was dissolved either in tartarate standard buffer solution at $\mathrm{pH} 3.5$ or in $12 \%$ ethanol tartarate standard buffer solution at $\mathrm{pH} 3.5$. The referred values of $\mathrm{pH}$ and ethanol percentage are the average values of table wines.

Wines from different regions of Portugal, namely Grão Vasco (Dão), A P_Cabernet (Setúbal), C P_Castelo de Syrah (Setúbal), Ol (Alentejo), A P (Alentejo) and Quinta dos Poços (Douro), were studied. Grão Vasco was taken as a reference. It was observed that Grão Vasco (Dão) wine presented a caffeic acid equivalent concentration superior to the other studied wines, followed by a Douro wine: Quinta dos Poços (values of 17.00 and $12.18 \mathrm{mg} / \mathrm{L}$, respectively, were found). It was also possible to verify that the two latter referred wines did not inhibit the biosensor, which could be reused after having been dipped in those wines. However, the wines from Setúbal and Alentejo, studied in this work, have a caffeic acid equivalent concentration lower than the other two mentioned before and seemed to inhibit the system, since the biosensor response decreased after being used in them. It was, thus, not possible to do several assays with the same membrane, when those wines were used. Reproducibilities were better for caffeic acid standard solutions, Grão Vasco and Quinta dos Poços wines, than for the other wines. In fact RSDs (Relative standard deviations) of the order of 1.1, 1.4 and 5.0\% were obtained for caffeic acid standard solution, Grão Vasco and Quinta dos Poços wines, whereas 20\% was found in the Setúbal and Alentejo studied wines. Two particular wines, A P_Cabernet and A P, were studied in more detail. Cyclic voltammograms and biosensor responses of these two wines indicate that $\mathrm{A} P$ has more caffeic acid equivalents than the A P_Cabernet.
\end{abstract}

Keywords: biosensor, wine, caffeic acid, voltammetry.

\footnotetext{
* Corresponding author. E-mail address: mjrebelo@fc.ul.pt
} 


\section{Introduction}

Tyrosinase, peroxidase, and laccase biosensors have been used for detecting phenolic compounds [1]. Laccase based polyphenolic biosensor has been previously used by us $[2,3]$.

Laccase is a type of copper-containing polyphenol oxidase ( $\mathrm{p}$-diphenol oxidase, EC 1.10.3.2) that oxidizes polyphenols, but it does not oxidize tyrosine (as do the tyrosinases). Laccases can be obtained from bacteria, fungi and some plants.

It has four copper ions. One of the copper ions is the site for the oxidation of the phenolic compounds and the other three are related to the reduction of oxygen to water [4].

We have been using caffeic acid in buffers at $\mathrm{pH} 3.5$ and 4.5 , as the substrate for laccase biosensors $[2,3]$. To our best knowledge, we were the first group studying the biosensor response to polyphenols at $\mathrm{pH} 3.5$, which is the most relevant $\mathrm{pH}$ value in wines.

In fact, Yaropolov et al. (1995) [4], Lo Gorton et al. (2004) [5] and Pingarrón et al. (2006) [6] studied caffeic acid biosensors at pH 5.0; Pingarrón et al. (2005) worked at pH 7.4 [7]; and Campanella et al. (2004) had their buffer at pH 8.5 [8], when they studied biosensor responses to polyphenols as standards in order to apply them in wine.

A very careful study of the electrochemistry of caffeic acid at a wide range of $\mathrm{pH}$ has been done by Giacomelli et al. [9]. Since it is reported that $\mathrm{pK}_{\mathrm{a} 1}=4.41, \mathrm{pK}_{\mathrm{a} 2}$ $=8.64, \mathrm{pK}_{\mathrm{a} 3}=12.513$, caffeic acid will be mainly in its protonated form at $\mathrm{pH}$ 3.5 , and its electrochemical behaviour changes when the $\mathrm{pH}$ increases to high values. In fact, at $\mathrm{pH} 8.5$, for instance, the present species will be the anion represented as $\mathrm{H}_{2} \mathrm{CAF}^{2-}$, that is, an anion with two negative charges, which will change the reduction potential.

The aim of the present work was to compare the caffeic acid equivalent content of wines different from those previously studied by us, measured by our biosensor. Cyclic voltammograms were also run for two particular wines.

\section{Reactions occurring at the electrode surface}

It is generally accepted that caffeic acid is oxidised by the immobilised laccase, being reduced back by the electrode, poised at appropriate potentials $(+100 \mathrm{mV}$ vs. $\mathrm{Ag} / \mathrm{AgCl}$ in the present case), as shown in Fig. 1.

Thus, the quinone formed is rapidly reduced back to caffeic acid, recycling it and amplifying the biosensor response. 


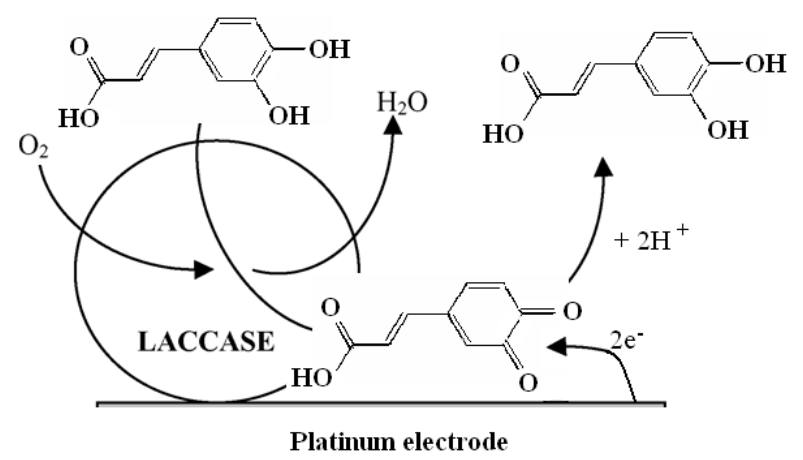

Figure 1. Scheme showing a simplified view of the oxidation of caffeic acid by laccase and subsequent reduction of the formed quinone, by the electrode.

\section{Experimental}

\section{Materials and reagents}

Laccase was 53739 from Trametes versicolor, EC (1.10.3.2), from Fluka. Caffeic acid: trans - 3,4- dihydroxycinnamic acid, was purchased from Aldrich. PBS (phosphate buffer saline) $\mathrm{pH}=7.4$, was prepared with $\mathrm{NaCl}$ from Riedel-deHaën with purity greater than $99.8 \%, \mathrm{KCl}$ from Merck with purity superior to $99.5 \%$; $\mathrm{Na}_{2} \mathrm{HPO}_{4}$ and $\mathrm{KH}_{2} \mathrm{PO}_{4}$, with purity superior to $99.9 \%$ and $99.7 \%$, respectively, both supplied by Sigma-Aldrich. Tartarate buffer was prepared with tartaric acid from Riedel-deHaën, Analytical reagent. Concentrated $\mathrm{KOH}$ from RiedeldeHaën was added to citric and tartaric acid to make the $\mathrm{pH}$ equal to 3.5 .

Caffeic acid solutions were freshly prepared at a concentration of $0.5 \times 10^{-3} \mathrm{~mol}$

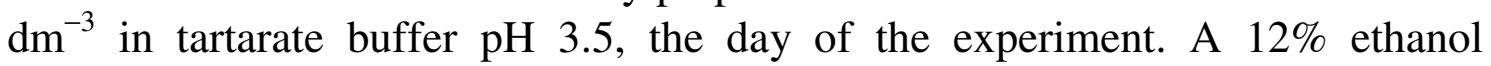
solution in tartarate buffer was also used.

Milli-Q A10, Millipore water was used to make up the solutions.

Polyethersulphone membranes (Ultrabind US450 $0.45 \mu \mathrm{m}$ ) were from Gelman.

\section{Equipment}

An Amperometric Biosensor Detector from Universal Sensors (New Orleans, USA) was used to apply the potential and acquire the resultant current. The electrode system was also from Universal Sensors, the 4208 base electrode consisting of $\mathrm{Pt}-\mathrm{Ag} / \mathrm{AgCl}$.

A Pharmacia Biotech recorder REC 102 was used to record the transient current vs. time.

\section{Methods}

Laccase solution samples were immobilized on derivatized polyether sulphone membranes. The amount of enzyme solution used in each membrane was $30 \mu \mathrm{L}$ containing $0.2 \mathrm{mg}$ of enzyme. The membranes with the immobilized enzyme were applied to a US electrode base system and the biosensor thus prepared was studied. A potential of $100 \mathrm{mV}$ was applied and the resultant current recorded. The current was due to the reduction of the quinones, which are the product of the laccase catalyzed oxidation of the phenolic compound. 
Caffeic acid was dissolved in tartarate buffer at pH 3.5 and used as the substrate. The wine assays were also done in tartarate buffer. The tartarate buffer was prepared with $0.033 \mathrm{~mol} \mathrm{dm}^{-3}$ tartaric acid and concentrated potassium hydroxide was added up to a $\mathrm{pH}$ value equal to 3.5. The biosensor was put into contact with $5 \mathrm{~mL}$ of the buffer, the potential was applied and the resultant base current was recorded. After stabilization of that current, injection of $50 \mu \mathrm{L}$ of $0.5 \mathrm{mM}$ caffeic acid in tartarate buffer $\mathrm{pH} 3.5$ was done. A cathodic current was observed to occur. The steady state value of the current was recorded and used for calculations. The solution was stirred with a magnetic stirring bar. Studies were also done with $12 \%$ ethanol tartarate buffer $\mathrm{pH} 3.5$. A volume of $200 \mu \mathrm{L}$ was used for the injection of wine samples.

\section{Results and Discussion}

\section{Repeatability and linearity of the biosensor}

The repeatability of the biosensor response to $5 \mu \mathrm{M}$ caffeic acid in tartarate buffer $\mathrm{pH} 3.5$ (Eap $=+100 \mathrm{mV}$ vs. $\mathrm{Ag} / \mathrm{AgCl}$ ) was very good. Values of $\Delta \mathrm{I}=$ $0.46 \mathrm{nA} \pm 0.0058$, that is a $\mathrm{RSD}$ of $1.3 \%$ were obtained for a series of five assays. The present results are very close to values previously found at our laboratory with citrate buffer ( $c a$. one year before): $0.414 \mathrm{nA} \pm 0.008, \mathrm{RSD}$ of $1.9 \%$ [3], which shows the good reproducibility of the system.

The linearity of the biosensor response to caffeic acid was also similar to the values previously found. That is, $\Delta \mathrm{I}=94.09 \mathrm{c}+0.080 \mu \mathrm{A} \mathrm{M} \mathrm{M}^{-1}, \mathrm{R}^{2}=0.995$.

\section{Caffeic acid equivalents of several wines}

The response of the biosensor to several Portuguese red wines was compared to the response to caffeic acid solution used as standard, and the content of caffeic acid equivalents for different wines shown on Table 1.

Table 1. Caffeic acid equivalent/(mg/L) of several Portuguese red wines.

\begin{tabular}{cc}
\hline Wine & Caffeic acid equivalent/(mg/L) \\
\hline Grão Vasco (Dão) & 17.00 \\
Quinta dos Poços (Douro) & 12.18 \\
A P_Cabernet (Setúbal) & 4.16 \\
C P_Castelo de Syrah (Setúbal) & 4.80 \\
Ol (Alentejo) & 3.24 \\
A P (Alentejo) & 8.30 \\
\hline
\end{tabular}

\section{Influence of the wines on the biosensor response}

The possibility of using the biosensor for successive analysis of different wines was studied. It was observed that some wines did not spoil the system which could be reused after having been applied to those wines (Grão Vasco and Quinta dos Poços). Other wines caused a decrease on the biosensor response. This decrease on the response was checked by measuring the response of the biosensor to caffeic acid solution before and after the measurements in wine. The difference in behaviour is still under study. As there was not a previous 
knowledge of the effect of the wines on the biosensor response, a new membrane was used for each experiment and they were disposed of, after use.

\section{Comparative study of $A$ P and $A$ P_Cabernet wines}

An A P_Cabernet wine was compared to A P wine. Both the biosensor responses and cyclic voltammograms were run. It was observed that A P had more caffeic acid equivalents than the corresponding A P_Cabernet, as measured with the biosensor. The evolution of the caffeic acid equivalent content of those wines with time is shown in Fig. 2.

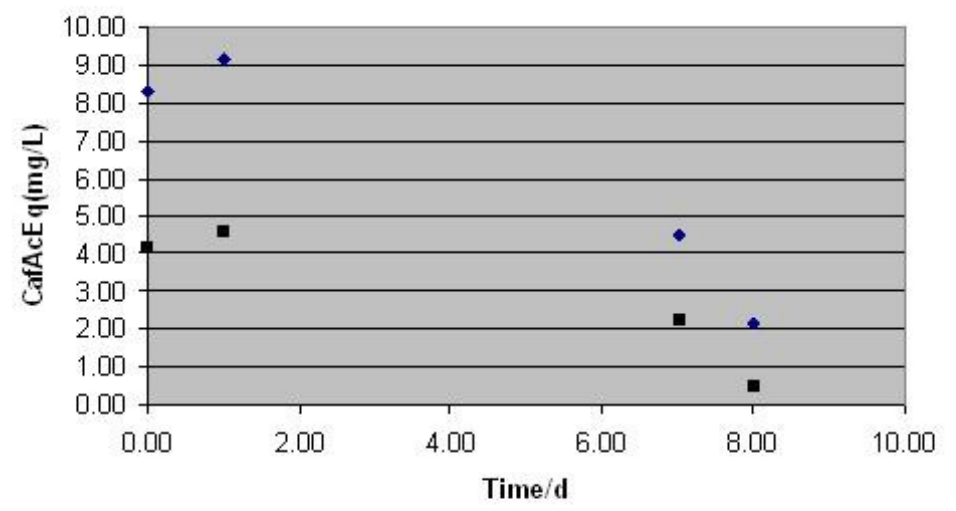

Figure 2. Variation of caffeic acid equivalent (mg/L) of A P ( $\square$ ) and A P_Cabernet $(\square)$ wines with time.

Cyclic voltammograms were run on those wines, as well as on caffeic acid in tartarate buffer and on the buffer alone. They are shown in Fig. 3.

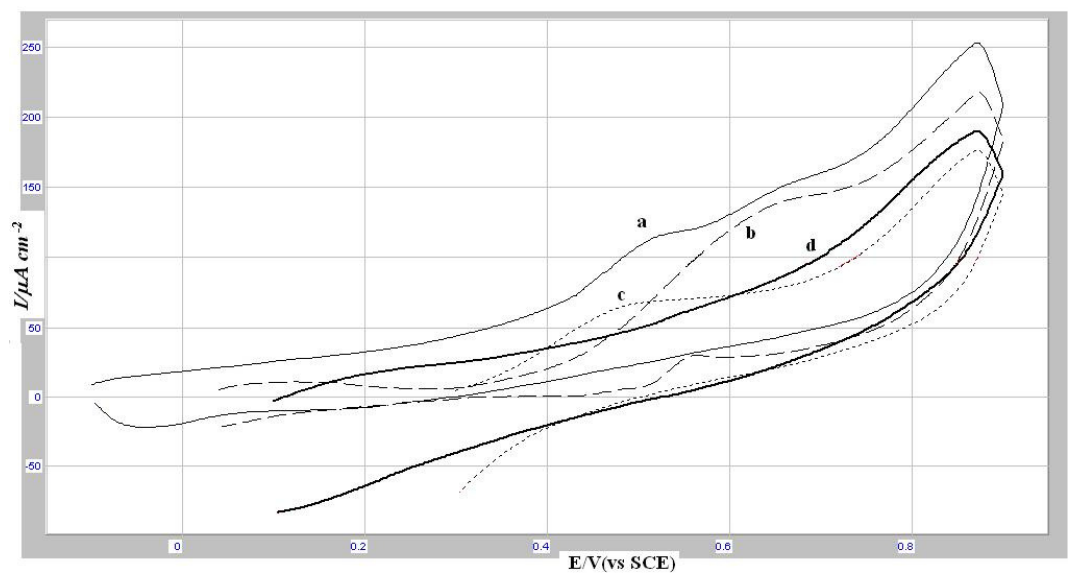

Figure 3. Cyclic voltammograms of A P (a) and A P_Cabernet (b) wines vs. $0.5 \mathrm{mM}$ caffeic acid in $0.033 \mathrm{M}$ tartarate buffer $\mathrm{pH} 3.5$ (c), and $0.033 \mathrm{M}$ tartarate buffer $\mathrm{pH} 3.5$ (d). $\mathrm{WE}=\mathrm{Pt}$ disc; $\mathrm{AE}=\mathrm{Pt}$ wire; RE: SCE. $v=100 \mathrm{mV} / \mathrm{s}$. 
It can be observed that $\mathrm{A} \mathrm{P}$ wine has a maximum near the region where caffeic acid has ( $c a .500 \mathrm{mV}$ vs. SCE), whereas the AP_Cabernet wine has its maximum at more positive potentials and, thus, has less antioxidant capacity than AP wine. This latter mentioned observation is in agreement with a somewhat similar situation reported by De Beer et al. (2003) [10], who found that a Ruby Cabernet wine had less total phenols than Merlot wines and also lower \% MLP(microsomal lipid peroxidation ) inhibitory activity.

\section{Conclusion}

The application of a biosensor for the determination of the polyphenolic content of wine was extended to wines not previously studied. Cyclic voltammetry was also run and it was observed that the $\mathrm{A} P$ wine had more caffeic acid equivalents than the corresponding A P_Cabernet, as measured both with the biosensor and by cyclic voltammetry. Some of the studied wines seemed to affect the biosensor and, so, it is recommended that a new membrane is used for each experiment and disposed of, after use.

\section{References}

1. L.D. Mello, L.T. Kubota, Talanta 72 (2007) 335-348.

2. S.A.S.S. Gomes and M.J.F. Rebelo, A New Laccase Biosensor for Polyphenols Determination, Sensors 3 (2003) 166-175.

3. R.S. Júnior and M.J.F. Rebelo, Biosensors for the polyphenolic content of wine determination, Port. Electrochim. Acta 26(1) (2007) 117-124.

4. A.I. Yaropolov, A.N. Kharubiu, J. Emnéus, G. Marko-Varga, L. Gorton, Anal. Chim. Acta 308 (1995) 137-144).

5. A. Jarosz-Wilkołazka, T. Ruzgas, L. Gorton, Enzyme and Microbial Technology 35 (2004) 238-241.

6. M. Gamella, S. Campuzano, A.J. Reviejo, J.M. Pingarrón, J. Agric. Food Chem. 54 (2006) 7960-7967.

7. V. Carralero Sanz, M.L. Mena, A. González-Cortés, P. Yáñez-Sedeño, J.M. Pingarrón. Anal. Chim. Acta 528 (2005) 1-8,

8. L. Campanella, A. Bonanni, E. Finotti, M. Tomassetti, Bios. Bioelectron. 19(7) (2004) 641-651.

9. C. Giacomelli, K. Ckless, D. Galato, F.S. Miranda and A. Spinelli, J. Braz. Chem. Soc. 13(3) (2002) 332-338.

10. D. De Beer, E. Joubert, W.C.A. Gelderblom and M. Manley, J. Agric. Food Chem. 51 (2003) 902-909. 